\title{
BOOK REVIEW: HUMAN RIGHTS IN THE SOUTH PACIFIC CHALLENGES AND CHANGES
}

\author{
Catherine Harwood*
}

Sue Farran Human Rights in the South Pacific Challenges and Changes (Routledge-Cavendish, United States and Canada, 2009).

Sue Farran's text Human Rights in the South Pacific is a crucial resource to aid understanding of the current state of rights in the Pacific region and further their realisation. The Pacific as a geographical region has no charter or declaration of human rights. In addition, as I write this review, tensions mount in Fiji. The Fijian President has dissolved the Constitution, postponed elections, dismissed Court of Appeal judges who ruled that the interim government was illegal, and silenced media that challenged the Government's actions. Consequences of this political unrest include the threat or actual loss of freedom of expression, the right to vote, freedom of movement and the right to natural justice. Such events reveal the potentially precarious existence of human rights in some Pacific states, and show that a vigorous human rights debate is needed to further realise human rights.

Human Rights in the South Pacific examines themes and tensions raised by rights in Pacific states that have common law as part of their legal frameworks. The text ponders the notion of human rights with a view to increasing awareness of their value and establishing workable mechanisms to bolster human rights in the Pacific, whether that is via a regional apparatus or statespecific initiatives. While the text offers no definitive solution, it provides a platform of ideas from which meaningful discourse on human rights can spring.

The opening page of the text states that it will appeal to "anyone interested in the region or in human rights..." While this describes the intended audience rather broadly, the text has relevance for students, academics, practitioners and policy makers alike. It is also a valuable resource for Pacific peoples who have few texts of this depth on the subject of human rights devoted entirely to their region.

* $\quad$ BA, LLB(Hons); Judges' Clerk, New Zealand Court of Appeal. 
The book has five main themes: existing human rights recognition and enforcement; theoretical underpinnings to rights; the intersection between human rights and property law; challenges inherent in the inclusion of rights concepts into the Pacific and finally, suggestions for 'taking rights forward' through national, regional and international initiatives.

Before the book's themes are discussed in depth, its context ought to be considered. Author Sue Farran gained firsthand experience of the Pacific rights milieu after spending five years as Senior Lecturer and Associate Professor at the University of the South Pacific, based in Vanuatu, for which she remains a visiting lecturer. She is now based in Scotland as Senior Lecturer at the law school of the University of Dundee. Farran has published books and papers on a number of topics, notably comparative analyses of the Pacific and other regions in the context of human rights, property, family and development law. While Farran acknowledges that her perspective is that of a "white, female, non-Pacific islander" (at iii) her insights are informed, reflecting her experiences in and knowledge of the societies of which she writes.

The text is written as a series of self-contained chapters, each with their own set of footnotes. The text is however centrally organised with a universal list of cases, legislation, acronyms and abbreviations, glossary and index. The Contents indicates chapter divisions, but a reader wishing for a more detailed prescription will need to consult the index. In addition to pinpoint citations at the end of each chapter, at the rear of the text is a comprehensive bibliography. In general, the book is user-friendly, perhaps envisaging a holistic reading rather than inviting reduction of information into technical paragraphs.

Farran's text is different from the papers in this journal. It depicts with a broad brush the picture of human rights in the South Pacific. The book does not, however, profess to be a correct or complete statement on human rights. Farran does not attempt to convince the reader that her view is more balanced, neutral or persuasive, but states in the Introduction that "[i]f the subject matter contained herein does nothing more than provoke contrary views or debate then one of its aims will have been achieved" (at iii). While rights can be manifested in a myriad of ways, critical discourse is the first step towards reaching a workable outcome.

The Introduction sets out, broadly, three political positions regarding human rights in the region. First, human rights may be viewed as an alien imposition suggesting imperialist domination. Second, rights are perceived as having always existed in the Pacific, but are given effect in culturally specific ways. Finally there is a middle ground, which sees commonalities between western and Pacific notions of rights and aims to reconcile differences where possible.

The first view is often muted in formal discussions of human rights. It sees changes to the legal framework from outsiders - as has mainly occurred in the Pacific - as western colonialism on a global scale, legitimised by 'international' (but really western-driven) bodies and treaties. The second view is underpinned by a belief that human rights exist universally or at least across cultures, with diverse manifestations. Explanations seek to show how basic human dignity is respected 
through cultural practices, albeit in a non-western fashion. A good example of this is the description of Samoa's gendered labour division and cultural values in Unasa Vaá's article in this edition of the VUWLR.

The third view, taken by the New Zealand Law Commission in "Converging Currents: Custom and Human Rights in the Pacific" (Study Paper 17, Wellington, 2006) aims to reconcile apparently different practices by identifying common underpinnings. The general tenor of this text is that human rights in their 'modern' form are desirable and ought to be part of Pacific law, but must reflect Pacific realities. Farran notes at page 53 that any conception of rights will only be workable in the Pacific if principles "adapt to new circumstances and environments" and indigenous laws "accommodate non-indigenous concepts of human rights".

Farran is careful to point out that analysis may veer from general to specific and back again, and does not try to package up the entire Pacific experience with sweeping discourse. A useful first chapter is entitled "The region of the Pacific" and introduces the foreign - or indeed uninformed local - reader to the geographical and socio-political landscape. One fact that this reader was unaware of was the skewed population spread: 91 per cent of the entire South Pacific population is resident in Melanesia (comprising of Papua New Guinea, Solomon Islands, Vanuatu, and parts of Fiji), with Papua New Guinea containing 70 per cent of the total population alone. Local factors influence the ultimate manifestation of rights so the inclusion of geographical information puts the rights discussion in context.

A discussion of the (often tenuous) distinction between 'custom' and 'customary law', included in Chapter Five, perhaps would have been more advantageously placed at the outset of the text. Readers who are unfamiliar with discussions of indigenous legal systems may perceive a gap between 'custom', 'customary law' and 'law', assuming that legal legitimacy only belongs to Western social rules in the western tradition and that non-western societies are organised by systems of rules that lack legal status. Apart from this omission, the chapter discusses leadership and governance structures, the relationship with (and influences from) other parts of the world and the provision of aid, making this a versatile introduction to the Pacific for any legal research into the region.

Chapter Two examines the formal sources of human rights in the Pacific. The author explains what is meant by the term 'human rights', acknowledging that for some, they are the "corollary of duties"; while for others they are "the entitlement of all people regardless of their status, location, legal system or any other context"; and yet concludes that "the modern concept of human rights is largely a legal one", framed as laws and implemented by the state (at 51). This irresistibly raises the question: whose law? Farran states that the idea of individual freedom is "associated with western style democracies" (at 53). While most Pacific countries had common law and state apparatus introduced into their legal systems, they are often incorporated within or alongside the indigenous legal order. While sources of rights are transversed in detail, it would have been valuable, at least for this reader, to have a wider discussion of customary conceptions of rights, or values that are rightsconsistent, in order to fully appreciate the intersections between 'traditional' and western principles. 
The third chapter, "Theories and approaches to human rights", outlines jurisprudence underpinning the human rights movement. Farran describes the difference between naturalist and positivist conceptions of the legitimacy of rights. The trouble with both these perspectives is that they do not explain why human rights in their current form should be part of Pacific legal frameworks. The naturalist viewpoint is often coupled with universalist philosophy, positing that human rights exist outside technical legal orders and are rooted in the inherent dignity of the human being. However, rights reflect important social values, and the emphasis on the individual in the western tradition of rights may not be a perfect fit for Pacific cultures, which also recognise group rights and responsibilities. Are these 'false' rights? Or does this mean that some 'fundamental' rights may be more relative to the societies from which they derive than proponents would care to admit? Conversely, positivism holds that rights derive status from their position as part of the binding 'legal' order. Does this mean, in societies which did not protect rights with western-style state apparatus, that human rights in those systems are not legitimate? We are left with a lack of theoretical underpinning for the justification for human rights. Perhaps it is the emotional response that 'human rights are good', which really drives their enactment. Farran however does not see the lack of an answer to the philosophical underpinning of rights as a limitation; rather she sees it as an opportunity for societies to put their own stamp on the idea. Universal rights could be interpreted and given local effect through a relative philosophical understanding (at 107-108).

What is largely absent from the discussion of approaches to human rights is a critical analysis of the objection to rights as a vehicle for a new brand of colonisation. Behind some rhetoric of human rights is a belief in 'progress', 'civilisation', 'basic standards' and democracy, which moves from the non-western towards western conceptions of society. While colonisation by nations has virtually ceased, some theorists argue that colonisation by global powers has only just begun. A revision of the whole of the rights debate would, in my view, benefit from an explanation of this position as a counter-movement to the expansion of formal human rights into non-western nations.

Farran moves away from abstract notions of 'rights' and into legal realities of the South Pacific in the fourth chapter entitled "Fundamental rights and questions of property." Farran considers the right to own property to be fundamental, worthy of first mention because physical geography is "fundamental to identity, existence and survival" (at 122) with links to land both temporal and spiritual. Land is particularly vulnerable to overseas investment and purchase, with resulting pollution, deforestation and urban development. There is also tension between individual and group rights, signifying a clash between Pacific and western notions of 'ownership'. Farran discusses the difficulties with intellectual property, water rights and rights to a sustainable environment, challenged by global warming. The issue of property law is obviously not able to be fully traversed in one chapter. While each section is not exhaustive, it does provide a good summary as to the key difficulties faced, with examples from different nations to tie legal theory to reality.

The fifth chapter, "Social ordering", explains the junction between indigenous custom and international human rights law. Most of the discussion centres on discrimination against women, 
who often experience inequality and under-representation in public life. There is a need to tread carefully, as one may either be accused of paternalism or as being overly relativist. Farran states that arguments against the inclusion of rights are sometimes "used as a cloak to conceal human rights abuses" (at 162). They are also used to protect traditional power structures, which may be disrupted by democracy. Farran muses that in evaluating culture, we must be sure that all voices are heard for only then can we appreciate the extent to which a culture values dignity and respect for its people (at-190-191).

The next chapter, "Freedom from discrimination", examines more widely the experience of disparate treatment. The elevated social position of matai in Samoa and the ethnic restrictions on land ownership in Fiji are given as examples of inequalities. Discrimination on grounds of sexuality, transgender status, religion and ethnicity is canvassed. The discussion of religion is pertinent, as it continues to be a dominant feature of Pacific societies, in an age where in western cultures traditional church attendance is waning. Religion is also a powerful form of social cohesion and sanction, which can effect the continuation of other forms of discrimination. Farran concludes that protection for a minority is best achieved by framing rights in the negative (universal protection from discrimination on listed grounds) rather than the positive (protection for certain groups). She points out that to separate certain groups as deserving of protection may "aggravate, not ameliorate" discrimination, as intervention can be seen as the injection of "western liberal agnostic values" in the face of religious morality (at 229). Recognition that vulnerable groups need support to participate fully in society is useful, but needs to be realised in a manner which will not be met with obstruction. Conventions such as the Convention on the Elimination of Discrimination Against Women (CEDAW) and United Nations Convention on the Rights of the Child (UNCROC) are useful to declare and raise awareness of rights, and some Pacific states have signed up to these.

The realistic assessment of the implementation of anti-discrimination law leads to the seventh chapter, "Rights advocacy and enforcement". It is true that rights are ineffective without a framework on which to peg them. The real challenge exists in identifying the best mechanism to effect rights in a meaningful way for the society in which they are to be implemented. The answer for Farran lies not in an unswerving acceptance of United Nations dogma, but the creation of a "more diversified approach" (at 235) involving formal government, courts, human rights commissions, NGOs, the media and civil society to create a complex web of rights enforcement.

The difficulties in implementing a regional human rights body have been discussed at length in the aritlces in this review. Due to a lack of resources, and suspicion regarding the motives of more powerful states such as Australia and New Zealand, a regional initiative may at this stage be more realistic as an aspirational body than one with real 'teeth' of enforcement. It is also unrealistic to expect some national governments, which are still finding a firm footing after independence, to have the personnel or inclination to make broad statements of rights. In some states, basic social stability is under threat. Perhaps a 'softly softly' approach is not timid but pragmatic. 
The final chapter, "Taking rights forward", looks ahead at possible directions to increase the impact of human rights in the South Pacific. Farran cites Freeman (Human Rights: An Interdisciplinary Approach (Polity Press, Cambridge, 2002) 135) who observes that many Pacific states 'talk the talk' about human rights without 'walking the walk'. Lord Cooke of Thorndon once spoke of the danger of 'window-dressing' rights; and indeed the formal enactment of human rights is nothing without enforcement. However, the recognition of rights is the vital first step towards their realisation. The law should not be hollow, but it is also an important stimulus of the collective legal conscience.

The text covers a lot of ground, which sometimes requires a sacrifice of depth for breadth. In short, it is accessible, informative and an important contribution to the continuing rights debate in the Pacific. Events that continue to unfold in Fiji remind this reader that human rights are, while contestable in form and substance, invaluable in terms of their basic existence. It raises awareness and provides tangible suggestions for change. If the text aids greater understanding of human rights for and by Pacific peoples, it will have performed a valuable service indeed. 